Original Research Article

\title{
Frequency of stroke patients qualified for recombinant tissue plasminogen activator (r-TPA) injection and limitations in Zahedan 2016
}

\author{
Alireza Khosravi $^{1 *}$, Mohammad-Taghi Farzadfard ${ }^{2}$, Arezoo Abdollahpour ${ }^{1}$
}

${ }^{1}$ Clinical Immunology Research Center, Department of Neurology, Zahedan University of Medical Science, Zahedan, Iran

${ }^{2}$ Department of Neurology, School of Medicine, Mashhad University of Medical Sciences, Mashhad, Iran

Received: 25 October 2017 Accepted: 24 November 2017

\section{*Correspondence to:}

Dr. Alireza Khosravi,

Email: alirezakh25@gmail.com

Copyright: (C) the author(s), publisher and licensee Medip Academy. This is an openaccess article distributed under the terms of the Creative Commons Attribution NonCommercial License, which permits unrestricted noncommercial use, distribution, and reproduction in any medium, provided the original work is properly cited.

\begin{abstract}
Background: Stroke is one of the common causes of mortality and disability. By introducing r-TPA into the global drug market and its effect on the patients' prognosis, using this drug is recommended in all patients with ischemic stroke who visited less than 4.5 hours after stroke and do not have contraindications. The aim of this study was to investigate the frequency of stroke patients qualified for recombinant tissue plasminogen activator (r-TPA) and its limtations.

Methods: In this descriptive cross-sectional study, 244 patients examined with stroke admitted to the Neurology Department of Zahedan city hospital in 2016. Information form were completed with demographic data, transmission method, referral time, CT scan preparation time, and the response of the patients' trials, and finally the data were inserted in SPSS.16 software and analysed by statistical methods.

Results: Out of all patients with ischemic stroke, $28(11.5 \%)$ patients had contraindication to receive drug. Of 216 remain patients, 201 patients $(93.1 \%)$ had no possibility to receive r-TPA due to the loss of golden time and only 15 patients $(6.9 \%)$ had possibility to receive drug because of visited 4.5 hours before the beginning of symptoms. Of them, $3(20 \%)$ patients due to delay in CT scan and test results, had no possibility to receive r-TPA. In summary, of all patients with inclusion criteria, only $12(5.5 \%)$ patients could use the r-TPA in this study. Conclusions: The most important barrier to using r-TPA has been the loss of golden time and training to raise awareness of the society can lead to early referral from the onset of stroke symptoms.
\end{abstract}

Keywords: Ischemic stroke, Recombinant tissue plasminogen activator (r-TPA), Restriction

\section{INTRODUCTION}

The stroke refers to the sudden occurrence of focal neurological defects which can be caused by blood circulation abnormalities in the brain, retin and spinal cord and lasts more than 24 hours. hemorrhage and Ischemia are two main causes of stroke. In worldwide, stroke is the fifth leading cause of death. ${ }^{1}$

Every year 750000 new strokes have been occurred and nearly 150000 people die in the United States due to stroke. $^{2}$ Even though the incidence of stroke in high income countries including the United States is declining but its incidence in low income countries is still rising and in general, it can be said that the global burden of stroke disability is still high. ${ }^{3,4}$

Stroke is classified in two groups: Ischemic and hemorrhagic stroke. According to studies the prevalence of stroke is different in terms of geographically, environmentally and genetically in different regions. 5,6

Doing study is required in each region of the country to determine the eptdemiologic condition, common risk 
factors and burden of disease. Ultimately these studies can lead to proper training and help to treatment trend of this disease.

Stroke in addition to the neurological defect in stroke patients, causes to other complications included cardiac arrhythmias, MI, pneumonia and neurogenic pulmonary edema which all of them increase mortality and disability of the patients. For a long time, treatment for patients with stroke was supportive and there was no certain treatment for this but with the entry of the venous and arterial thrombolytic into the global pharmaceutical market a window of hope for stroke patients was opened. Unfortunately, the use of this drug requires its immediate use from the start of symptoms.

Intravenous thrombolysis as an interventional therapy in the early 4.5 hours of start of symptoms, can reduce the incapacity and fatality associated with ischemic stroke and improve the patient's performance over the next 3 to 6 months. $^{7}$ Many studies have been conducted on the efficiency of this drug and acceptable results are presented by injection of this drug between 3 and 4.5 hours after the star of the symptoms. ${ }^{8}$

However the use of this drug requires the suitable knowledge of the society in identifying stroke symptoms, early referral the quality and speed of laboratory and imaging services, timely visits by neurologist, early treatment and observe certain clinical principles. For this reason despite the need for r-TPA in at least $40 \%$ of people diagnosed with stroke, unfortunately this rate is much lower than the ideal in the world in many countries and especially in Iran and the most important cause in most studies is the loss of timely referral after symptoms start. ${ }^{9-}$ ${ }^{11}$ In this study we decided to evaluate the possibility of using r-TPA by venous injection in hospitalized patients with ischemic stroke in the neurology section of Zahedan city hospital and the frequency of patients who are qualified for r-TPA have been determined and also consider the limitations in Zahedan regarding the drug receive included: the operation of ambulances in patient transmission, delay in CT scan and lab, non-timely referral and the presence of contraindication for drug intake.

\section{METHODS}

This study was conducted on 244 patients with ischemic CVA in neurology clinic of Zahedan city hospital from April to the March 2016. It was a descriptive crosssectional study. A checklist containing information on age, sex, history, examination, time of CT scan, response time of the tests and patient transfer method to the hospital was completed for all patients.

\section{Inclusion criteria}

Patients with confirmed CVA according to neurologist diagnosis and brain CT-scan included in the study.

\section{Exclusion criteria}

Patients with hemorrhagic CVA according to Brain CTscan, internal bleeding, Intercalary hemorrhage, uncontrolled BP, use of LMWH in last 24 hours, PTT $>40$, PT $>15$, INR $>1.7$, Platelet count $>100000$ and serious trauma to the head excluded from study.

\section{Statistical analysis}

Collected data were analysed using statistical methods in SPSS 19.

\section{RESULTS}

The mean age of patients was 63.1 years. Of all patients, $33(13.5 \%)$ under the age of 45 were suffering from ischemic stroke. $125(51.2 \%)$ of patients were female and the rest were male. Of all patients with ischemic stroke, 28 patients had contraindications to receiving the r-TPA which excluded from the study (Table 1).

Table 1: Characteristics of patients in the study.

\begin{tabular}{|l|ll|l|}
\hline \multirow{2}{*}{ Variables } & Groups & n & $\%$ \\
\hline \multirow{2}{*}{ Sex } & $<45$ years & 33 & 86.5 \\
\cline { 2 - 4 } & $>45$ years & 211 & 13.5 \\
\hline \multirow{2}{*}{$\begin{array}{l}\text { Indication for receive } \\
\text { r-TPA }\end{array}$} & Male & 119 & 51.2 \\
\cline { 2 - 4 } Laboratory coagulation & Female & 125 & 48.8 \\
\cline { 2 - 4 } disorders & - & 216 & 88.5 \\
\hline \multirow{2}{*}{ Warfarin use } & Normal & 28 & 11.5 \\
\cline { 2 - 4 } & Non-normal & 19 & 7.8 \\
\hline \multirow{2}{*}{ Blood Pressure } & + & 10 & 4.1 \\
\cline { 2 - 4 } & - & 234 & 95.9 \\
\hline \multirow{2}{*}{ Possibility to use r-TPA } & Controlled & 235 & 96.3 \\
\cline { 2 - 4 } & Un-controlled & 9 & 3.7 \\
\cline { 2 - 4 } Transmit by ambulance & No & 12 & 4.9 \\
\cline { 2 - 4 } & Yes & 232 & 95.1 \\
\cline { 2 - 4 } & No & 160 & 74.1 \\
\hline
\end{tabular}

Of the qualified recipients of r-TPA, only 15 patients $(6.9 \%)$ could to the hospital at golden time less than 4.5 hours after the start of symptoms. But among them, $3(20 \%)$ due to lack of timely CT-scan and failure to get early result of the tests unable to receive the r-TPA. So, in total only $12(4.9 \%)$ had possibly received r-TPA.

\section{DISCUSSION}

The rate of ischemic stroke in this study was $75.3 \%$ which was similar to Maghoul and et al with $78 \%$ and Mazaheri et al with $79.9 \% .^{12,13}$

Of all patients, $211(86.5 \%)$ over 45 years of age had ischemic stroke. In the study of Maghoul et al, $84 \%$ of patients had over 60 years of age which indicating that the 
prevalence of stroke in young people in Zahedan city was higher than of other cities. ${ }^{12}$

The mean age of all patients was 63.09 years, the female was 62.4 years and male were 63.85 years which lower than other studies but in Iranmanesh study, the average age of patients was 62.59 years which was lower than present study. In general, it can be concluded that ischemic stroke occurs in Zahedan at earlier age. .,12-14 $^{-1}$

In this study, $125(51.2 \%)$ of patients were female and 119 $(48.8 \%)$ were male which was in line with other studies. $^{12-14}$

In this study, 216 patients were enrolled in the study and were evaluated. Unfortunately, due to the limitations, only $12(4.9 \%)$ patients were qualified for this drug and other people were not allowed to receive r-TPA due to the loss of golden time and failure to early test results and CT scans. In the study of Hatamabadi, among the 151 patients eligible for r-TPA only 3 patients could be used r-TPA and in the study of Mozhdehi-panah this rate was $8 \%$ slightly higher than the current study and this rate was $16 \%$ in the Casetta study. ${ }^{11,15-16}$

In this study the major limitation of receiving r-TPA was due to the lack of early referral of patients to the treatment center and in total $93.1 \%$ of patients who have indication for taking the drug did not have the luck for use r-TPA due to loss of golden time. In the study of Hatamabadi, the important limitation of drug receive was the loss of golden time and in $70.3 \%$ of patients r-TPA was not usable. In the Casetta study, the lack of patient decision was the most important cause and in the study of Mozhdehi-panah the most important reason was the delay in the visit by neurologist with $75 \% .^{11,15-16}$

Of the 216 patients with ischemic stroke who had indication of receiving r-TPA only 15 patients referred to the hospital during the golden time and other patients stayed away from the possibility of receiving r-TPA due to late referral. Of 15 patients who have come the right time and had indication receiving r-TPA, 3 patients due to lack of CT scan results before 4.5 hours and 2 patients due to failure to get early result of tests less than 4.5 hour did not allow for receiving r-TPA.

In the study of Hatamabadi, $20.9 \%$ of patients due to drug contraindication, $5.4 \%$ due to lack of beds in the intensive care unit (ICU) and 3.4\% due to lack of financial support were excluded from r-TPA use.

In the study of Mozhdehi-panah after delay in the visit by neurologist, the most important factors in preventing drug intake were the delay of patients in referring to medical centers with $67 \%$, delay in the preparation of the tests with $46 \%$, delay in the visit of physician with $39 \%$, delay in the ready of CT-scan with $36 \%$, taking antiplatelet drugs with $35 \%$ and use of anticoagulants $26 \% .^{11-15}$

\section{CONCLUSION}

Even though a high percentage of patients with ischemic stroke admitted to the neurology clinic of Zahedan hospital were potentially candidates for r-TPA, unfortunately only in a limited number of patients, r-TPA could be used and the most important reason for drug use limitation was firstly the loss of golden time and secondly delay in getting the CT scan and failure to get early tests results.

\section{Funding: No funding sources}

Conflict of interest: None declared

Ethical approval: The study was approved by the Institutional Ethics Committee

\section{REFERENCES}

1. Towfighi A, Saver JL. Stroke declines from third to fourth leading cause of death in the United States: historical perspective and challenges ahead. Stroke. 2011;42(8):2351-5.

2. Lashgharipoor K, Moghtaderi A, Sadjadi A, Faghihinia M. Prevalence of post stroke depression and its relationship with disability and lesion location. Journal of Fundamentals of Mental Health 2008;10 (39):191-9.

3. Koton S, Schneider AL, Rosamond WD, Shahar E, Sang Y, Gottesman RF, et al. Stroke incidence and mortality trends in US communities, 1987 to 2011. JAMA. 2014;312(3):259-68.

4. Feigin VL, Forouzanfar MH, Krishnamurthi R, Mensah GA, Connor M, Bennett DA, et al. Global and regional burden of stroke during 1990-2010: findings from the Global Burden of Disease Study 2010. Lancet 2014;383(9913):245-54.

5. Hosaini S.A, Bazrafshan H. A statistical study on the role of high-risk factors in the incidence of CVA. J Gorgan Univ Med Sci. 2001;3(2):76-80.

6. Khaw k. Epidemiology of stroke. J Neurol Neurosurg Psychiatry. 1996;61(4):333-8.

7. Lees KR, Bluhmki E, von Kummer R, Brott TG, Toni D, Grotta JC. Time to treatment with intravenous alteplase and outcome in stroke: an updated pooled analysis of ECASS, ATLANTIS, NINDS, and EPITHET trials. Lancet. 2010;375(9727):1695-703.

8. Boudreau DM, Guzauskas GF, Chen E, Lalla D, Tayama D, Fagan SC, et al. Cost-effectiveness of recombinant tissue-type plasminogen activator within 3 hours of acute ischemic stroke: current evidence. Stroke 2014;45(10):3032-9.

9. Bambauer KZ, Johnston SC, Bambauer DE, Zivin JA. Reasons Why Few Patients with Acute Stroke Receive Tissue Plasminogen Activator. Arch Neurol. 2006;63(5):661-4.

10. Kasmaei HD, Baratloo A, Nasiri Z, Soleymani M, Yazdani MO. Recombinant tissue plasminogen activator administration in patients with cerebrovascular accident; a case series. Arc Neurosci. 2015;2(2). 
11. Hatamabadi HR, Mansouri H, Asarzadegan F, Shojaee M. Barriers to On Time Delivery of Thrombolytic Therapy. J Mazandaran Univ Med Sci. 2013;23(102):107-10.

12. Maghoul A, Rezazadeh Kh, Majidinia M, Tadvinfar M, Akaberi A. Study of the prevalence of CVA cardiac Risk Factors in sabzevar (2005-2006). Beyhagh; J Sabzevar School Med Sci. 2007;15(1):11-6.

13. Mazaheri S, Beheshti F, Hosseinzadeh A, Mazdeh M, Ghiasian M. Epidemiologic Study of Cardinal Risk Factors of Stroke in Patients Who Referred to Farshchian Hospital of Hamadan during 2014-2015. Sci J Hamadan Univ Med Sci. 2016;22 (4):331-7.

14. Iranmanesh F, Salehi M, Bakhshi H, Arab R. Silent stroke and related risk factors. J Gorgan Univ Med Sci. 2013;15(1):90-4.
15. Mojdehipanah H, Yazdi Z, Nasiri MS, Azizlo Z. Barriers to delivery of tissue plasminogen activator for patients with acute ischemic stroke. Feyz J Kashan Uni Med Sci. 2015;19.

16. Casetta I, Granieri E, Gilli G, Lauria G, Rosaria Tola M, Paolino E. Temporal trend and factors associated with delyed hospital admission of stroke patient. Neuroepidemiol. 1999;18:255-64.

Cite this article as: Khosravi A, Farzadfard MT, Abdollahpour A. Frequency of stroke patients qualified for recombinant tissue plasminogen activator (r-TPA) injection and limitations in Zahedan 2016. Int J Basic Clin Pharmacol 2018;7:710. 